\title{
Two-Period Reputation Model of Knowledge Sharing between Enterprises Based on Signal Game Analysis
}

\author{
Qiliang Wang $\mathbb{D},{ }^{1}$ Qingquan Jiang $\mathbb{D}^{2},{ }^{2}$ Hongxia $Y u\left(\mathbb{D},{ }^{1}\right.$ Rong Fu $\mathbb{D},{ }^{3}$ and Changwei Mo $\mathbb{i D}^{4}$ \\ ${ }^{1}$ School of Economics \& Management, Zhejiang Normal University, Jinhua 321004, China \\ ${ }^{2}$ School of Economics \& Management, Xiamen University of Technology, Xiamen 361024, China \\ ${ }^{3}$ School of Business Administration, Hunan University, Changsha 410082, China \\ ${ }^{4}$ School of Economics, Xiamen University, Xiamen 361005, China \\ Correspondence should be addressed to Qingquan Jiang; jiangqingquan@xmut.edu.cn, Hongxia Yu; yuhx007@163.com, Rong Fu; \\ furong@hnu.edu.cn, and Changwei Mo; chwmo@xmu.edu.cn
}

Received 28 October 2020; Revised 20 March 2021; Accepted 29 March 2021; Published 13 April 2021

Academic Editor: Chenxi Huang

Copyright ( 2021 Qiliang Wang et al. This is an open access article distributed under the Creative Commons Attribution License, which permits unrestricted use, distribution, and reproduction in any medium, provided the original work is properly cited.

Knowledge sharing between enterprises is an important way to obtain external research and development (R\&D) resources and keep competitiveness. This paper used a reputation model based on a two-period signal game to explore knowledge-sharing micromechanism between enterprises and key influencing factors of enterprises. The results show that reputation effects are an important mechanism that will make knowledge sharing between enterprises operate effectively. Motivated by reputation effects, even those noncooperative enterprises continue to pretend to be cooperative enterprises for knowledge sharing before the end of the game. Finally, we adopt the analytical methods and conclusions given by the model in this article to analyze opportunistic problems in knowledge sharing among cooperative enterprises and put forward some valuable suggestions on the conditions for the effective use of corporate reputation effects.

\section{Introduction}

Innovation is inextricably related to the success of major enterprises. The importance of knowledge innovation in the growth of a company cannot be overstated [1]. Innovation is an important factor for an enterprise, and it is also one of the driving forces for the continuous development of an enterprise. As innovation complexity and uncertainty increase, the lack of corporate knowledge resources is unable to meet the needs of the era of accelerating product upgrades. Enterprises have to seek cooperation at all periods of innovation, so the exchange and sharing of knowledge between enterprises become the important ways to acquire external innovation resources and enhance innovation capabilities [2-4]. In this context, scholars all over the world have conducted some useful discussions on how to realize knowledge sharing between enterprises from the aspects of the supply chain, strategic alliance, and industrial clusters [5-10], which is very conducive to our understanding and mastery of knowledge sharing between enterprises.
However, due to the unique properties of knowledge, such as monopoly, concealment, and context dependence, the sharing of knowledge between enterprises has become particularly complicated [11-13]. It is not only different from the transfer of tangible materials in the general sense but also the market transaction in the pure sense [14]. Therefore, the micromechanism of knowledge sharing between enterprises is vital to the improvement of innovation capabilities of enterprises, as well as the focus and difficulty of knowledge management.

In collaborative innovation, although knowledge sharing between enterprises can bring synergy effects [15, 16]. However, the opportunistic behavior tendency of cooperative enterprises has become the biggest obstacle restricting knowledge sharing [17]. This kind of opportunistic behavior that seeks quick success can only obtain short-term benefits, but not long-term benefits, and it can also leave a bad corporate reputation [18]. Therefore, as an enterprise pursuing the maximization of its interest, it must balance shortterm and long-term benefits. When knowledge sharing is 
carried out in a multiperiod repeated game, the reputation effect will play a great incentive role, that is, the reputation of the previous period often affects the utility of the next period and subsequent periods, and the good reputation of the current period often means the future period has higher utility [19]. In other words, a noncooperative enterprise may pretend to be a cooperative enterprise for knowledge sharing, trying to establish a reputation for honesty and trustworthiness for itself, hoping to use the reputation for greater benefits when the game is about to end. The traditional reputation model represented by the KMRW reputation model generally considers repeated games. When performing static games is in a single period, neither dynamic games (such as signal games) nor the impact of decisions in the previous period on the utility of the next period is considered. In reality, these two situations are much common [20]. Given this, this article uses the theories from Kreps and Wilson [21], Milgrom and Roberts [22], Kreps, Milgromh, Roberts et al. [23], and others about the incentive effects of reputation on operator behavior in principal-agent relations and establishes a two-period reputation model based on the signal game, to explore the impact of corporate reputation on knowledge sharing between enterprises, and then reveal the microfunction mechanism and key influencing factors of knowledge sharing between enterprises.

\section{Two-Period Reputation Model on Knowledge Sharing between Enterprises Based on Signal Game Analysis}

In repeated game environments, reputation is a term that occurs when other players are unsure about some properties of one or more players. If "uninformed" players have an insight into past phase game results, reputation results will help aware players increase their long-run payoffs by eventually ensuring uninformed players that they relate to the type that fits best their objectives. They do so by consistently taking any action that helps them look too poorly informed players as if they are of the expected kind, thus "gaining a reputation" being of that type [24].

The economic concept of reputation states that if a patient player takes a specific action, others might assume him to repeat it in the future if it is against his short-term interest. He essentially has the freedom to agree to any action when earning (close to) Stackelberg payoffs for doing so. The signaling framework is much more tractable than traditional reputation models, yielding a special, quick, and calculable solution after refinement. Under both players general discount variables, the model remains solvable in general. Traditional reputational models allow for the reputation-builder to have a discount rate of 1 or close to 1, as well as myopic play by the other players, or at the very least a degree of tolerance that is significantly less than that of the reputation-builders. The claimant's discount factor has no impact on the solution in the repeated signaling model, and when the signaller's discount factor is less than 1, the outcome requires only that Stackelberg payoffs be replaced with clearly specified "discounted Stackelberg" payoffs [25].

2.1. Underlying Assumptions of Models. Due to the differences and gaps in the stock of knowledge and the level of knowledge, enterprises are constantly exchanging and sharing knowledge and generating huge synergies $[15,16]$. However, under the condition of information asymmetry, both parties or one party of knowledge sharing have motives to harm others instead of benefiting themselves. To maintain the stability and good operation of the cooperative relationship and to obtain greater knowledge sharing and collaboration effects, enterprises must establish an incentive mechanism for cooperation. A good reputation is undoubtedly an indispensable and important incentive mechanism for knowledge sharing between enterprises, which has an irreplaceable role in reducing information asymmetry or providing cooperative incentives $[18,26]$.

The sharing of knowledge is advantageous to enterprises, but it cannot be maintained. Knowledge can be enhanced by sharing it; however, knowledge sharing can also be harmful. The former will happen if people are willing to learn from one another. The latter is to be expected if the information is passed between people in insufficient representations [27]. Many enterprises developed strategies to share technical knowledge with rivals and firms that shared knowledge with their innovation mechanism performed better in terms of innovation than firms that did not. Furthermore, firms that connected with their global innovation process surpassed firms that only engaged with their regional innovation system in terms of innovative output [28].

The rational dissemination of information among agents is the importance of signal games to economic theory [29]. In this paper, we have constructed a two-period reputation model for knowledge sharing between companies based on the signal game.

\subsection{System Variable Description}

Assumption 1. (participant collection). Suppose two companies participate in knowledge sharing, that is, the set of participants is $N=\{1,2\}$. Each knowledge-sharing participating company $i$ is a rational person, taking maximization of self-interest as the basic principle of decision-making.

Assumption 2. (information completeness). In the first period, knowledge-sharing participating company 1 has the advantage of cooperating with the company 2 , that is, knowledge-sharing participating company 1 may choose to cooperate with company $2,(k=0)$, or not $(k=1)$, However, enterprise 2 does not know the type of knowledgesharing participating enterprise 1 , so the information in the first period is incomplete. Nevertheless, the equilibrium result of the signal game only contains the only separation equilibrium. The knowledge-sharing participating enterprise 2 infers that the posterior probability of enterprise 1 being cooperative $(k=0)$ is either 1 or 0 . In the second period, 
actions are taken according to this inference; therefore, the second period information is of complete information.

Assumption 3. (send signals and take action). In the first period, knowledge-sharing participating company 1 acts first and sends a signal $S_{1}$. Before sending the signal, it predicts what action company 2 will take. After receiving the signal, company 2 infers the type of company 1 and takes action $A_{1}$ according to the type of cooperation. In the second period, the knowledge-sharing participation in the signal game between enterprise 1 and enterprise 2 is described as above.

2.3. Reputation Effect Model Establishment. According to the above assumptions, the decision of the first period of knowledge-sharing participating company 1 affects the utility of the second period to a certain extent. Therefore, the two participating companies must fully consider their respective optimal decisions in the second period of the game in the first period. Next, we can use the reverse induction method to consider the whole process of knowledge-sharing participating in the signal game between company 1 and company 2 under the incentive scenario of reputation and nonreputation effect. The effect of reputation on the longevity of a monopolist selling single products in distinct periods can be slowly learned with consistency. A sufficiently bad run of luck could cause the seller to stop selling if she learns her quality at the same rate as customers. A good seller never stops selling when she knows her quality, though a poor seller would most likely do so when her reputation is low. Furthermore, whether her information is private or public, a seller with positive, but incomplete, information sells for the same number of periods [30].

\subsubsection{Analysis on the Model of Knowledge Sharing between} Enterprises without Reputational Effect Incentive. Suppose the utility function of the second period of knowledge-sharing participating enterprise 2 similar to Zhou, Gao \& Chen [31]:

$$
E_{2}\left(k, S_{2}, A_{2}\right)=c(k) S_{2} A_{2}-d A_{2}^{2},
$$

where $c(0)>c(1)>0$, the first item indicates the positive utility of the knowledge-sharing participating company 2 taking action $A_{2}$, which prefers the cooperative knowledgesharing participating company 1 . When $d>0, d A_{2}^{2}$, the second item indicates the negative utility of the knowledgesharing participating company 2 taking action $A_{2}$, that is, the cost action.

Solving the equation (1) for the first-order condition of maximizing the utility of $A_{2}$, the optimal response function of the second period of knowledge-sharing participating enterprise 2 is

$$
A_{2}^{*}\left(k, S_{2}\right)=\frac{1}{2} c(k) d^{-1} S_{2}
$$

From equation (2), it can be seen that the optimal response function of the second period of knowledge-sharing participating enterprise 2 is the increasing function of the signal sent by enterprise 1 in the second period. The stronger the signal sent by enterprise 1, the higher the optimal action of the knowledge sharing of participating company 2 .

Suppose the second period of the utility function of knowledge-sharing participating enterprise 1 is

$$
U_{2}\left(k, S_{1}, S_{2}, A_{2}\right)=a_{2} A_{2}-b_{2}(k) S_{2}^{2}-\eta S_{2}+\varphi_{2} S_{1},
$$

where $a_{2}>0$. The first item represents the positive effect of knowledge-sharing participating company 1 when the knowledge-sharing participating company 2 takes action $A_{2}$; $b_{2}>0, \eta>0$; the second and third items both indicate the negative utility of knowledge-sharing participation when enterprise 1 sends a signal $S_{2} \cdot \varphi_{2}>0$, the last item represents the positive utility of the signal $S_{1}$ sent by the first period of knowledge-sharing participating enterprise 1 to the second period.

After putting equation (2) into equation (3), we can get

$$
U_{2}\left(k, S_{1}, S_{2}, A_{2}\left(k, S_{2}\right)\right)=\frac{1}{2} a_{2} c(k) d^{-1} S_{2}-b_{2}(k) S_{2}^{2}-\eta S_{2}+\varphi_{2} S_{1} .
$$

In equation (4), the first-order condition of $S_{2}$ maximizing utility is obtained, and the optimal signal function of the second-period knowledge-sharing participating enterprise 1 is

$$
S_{2}^{*}(k)=\frac{1}{4} a_{2} b_{2}^{-1}(k) c(k) d^{-1}-\frac{1}{2} b_{2}^{-1}(k) \eta .
$$

$S_{2}$ has an information advantage due to the information asymmetry in the first step. As a result, when $S_{1}$ and $S_{2}$ play the game, the signal size in the second stage can be influenced by the utility in the first, and $S_{1}$ can pay more attention to the effect [31].

From equation (4), we can know that if $k=0$ and $S_{2}=0$, then $\partial U_{2}\left(0, S_{1}, 0, A_{2}(0,0)\right) / \partial S_{2}=1 / 2 a_{2} c(0) d^{-1}-\eta$. If $k=1$ and $\quad S_{2}=0$, then $\partial U_{2}\left(1, S_{1}, 0, A_{2}(1,0)\right) / \partial S_{2}=$ $1 / 2 a_{2} c(1) d^{-1}-\eta$. For $c(0)>c(1)$, then $\partial U_{2}\left(0, S_{1}, 0\right.$, $\left.A_{2}(0,0)\right) / \partial S_{2}>\partial U_{2}\left(1, S_{1}, 0, A_{2}(1,0)\right) / \partial S_{2}$. Therefore, we can infer that

$$
S_{2}^{*}(0)>S_{2}^{*}(1)>0 \text {. }
$$

It can be seen from equation (6) that when the information in the second period is complete, the optimal signal sent by the cooperative knowledge-sharing participating company 1 is higher than the optimal signal sent by the noncooperative knowledge-sharing participating company 1.

Suppose the utility function of the first period of knowledge-sharing participating enterprise 1 is

$$
U_{1}\left(k, S_{1}, A_{1}\right)=a_{1} A_{1}-b_{1}(k) S_{1}^{2}-\varphi_{1} S_{1},
$$

where $a_{1}>0, b_{1}>0$, and $\varphi_{1}>0$; other explanations are the same as the expression of the utility function of the second period of the knowledge-sharing participating company 1.

Suppose the utility function of the first period of knowledge-sharing participating enterprise 2 is 


$$
E_{1}\left(k, S_{1}, A_{1}\right)=c(k) S_{1} A_{1}-d A_{1}^{2},
$$

where $c(0)>c(1)>0$ and $d>0$, and other explanations are the same as the utility function of the knowledge-sharing participating enterprise 2 in the first period.

According to the system assumptions, the reputation signal size of knowledge-sharing participating company 1 in the first period affects its utility in the second period. Therefore, knowledge-sharing participating company 1 should pay attention to these effects from a long-term perspective. The setting $\delta$ is the discount factor of the enterprise. It represents the discount relationship between the first period utility and the second-period utility of knowledge-sharing participating enterprise 1 , and it can also express the patience of noncooperative enterprise 1 posing as a cooperative enterprise [32]. Then, the decision-making goal of the first period of knowledge-sharing participating company 1 is to maximize its two-period discounting utility.

$$
\begin{aligned}
\max U\left(k, S_{1}, A_{1}\right)= & U_{1}\left(k, S_{1}, A_{1}\right) \\
& +\delta U_{2}\left(k, S_{1}, S_{2}^{*}(k), A_{2}\left(k, S_{2}^{*}(k)\right)\right) \quad 0<\delta \leq 1 .
\end{aligned}
$$

It is the same as formula (2) and formula (5), which can be obtained, respectively.

The optimal response function of the first-period knowledge-sharing participating company 2 is

$$
A_{1}^{*}\left(k, S_{1}\right)=\frac{1}{2} c(k) d^{-1} S_{1} .
$$

The optimal signal function of the first-period knowledge-sharing participating company 1 is

$$
S_{1}^{*}(k)=\frac{1}{2} b_{1}^{-1}(k)\left(\frac{1}{2} a_{1} c(k) d^{-1}-\varphi_{1}+\delta \varphi_{2}\right) \text {. }
$$

Similar to the reasoning process of equation (6), we can also infer

$$
S_{1}^{*}(0)>S_{1}^{*}(1)>0 .
$$

It can be seen from equation (12) that, in the case of incomplete information in the first period, the optimal signal sent by cooperative knowledge-sharing participating company 1 is higher than the optimal signal sent by noncooperative knowledge-sharing participating company 1.

Combining formula (6) and formula (12), we can infer that, in the first and second periods, the optimal signal sent by cooperative knowledge-sharing participating company 1 is higher than that of noncooperative knowledge-sharing participating company 1 regardless of whether the information is complete or not. The best signal to send, that is, cooperative knowledge-sharing participating companies have no incentive to build a reputation in the first period, let alone use reputation in the second period. Relatively speaking, noncooperative knowledge-sharing participating companies 1 have the motivation to build a reputation in the first period.

2.3.2. Analysis on the Model of Knowledge Sharing between Enterprises Incentive by Reputation Effects. If long-term interest are considered, rational noncooperative knowledgesharing participating company 1 has to establish a reputation for honesty and trustworthiness in the first period and send a cooperative signal $\widetilde{S}_{1}^{*}(0)$ in the first period. In the second period, knowledge-sharing participating company 2 mistakes noncooperative company 1 for cooperative company 1 and will take demand action $A_{2}\left(0, S_{2}\right)$. Then, the two-periods discount utility function is

$$
\bar{U}\left(1, \widetilde{S}_{1}^{*}(0), A_{1}\left(0, \widetilde{S}_{1}^{*}(0)\right)\right)=U_{1}\left(1, \widetilde{S}_{1}^{*}(0), A_{1}\left(0, \widetilde{S}_{1}^{*}(0)\right)\right)+\delta U_{2}\left(1, \widetilde{S}_{1}^{*}(0), \bar{S}_{2}^{*}(1), A_{2}\left(0, \bar{S}_{2}^{*}(1)\right)\right)
$$

where $0<\delta \leq 1$ and other explanations are the same as formula (9). The utility function of the second period of noncooperative enterprise 1 is

$$
U_{2}\left(1, \widetilde{S}_{1}^{*}(0), \bar{S}_{2}^{*}(1), A_{2}\left(0, \bar{S}_{2}^{*}(1)\right)\right)=\frac{1}{2} a_{2} c(0) d^{-1} \bar{S}_{2}^{*}(1)-b_{2}(1)\left(\overline{S_{2}^{*}}(1)\right)^{2}-\eta \overline{S_{2}^{*}}(1)+\varphi_{2} \widetilde{S}_{1}^{*}(0)
$$

The solution method is the same as above, and the optimal signal function of the second period of noncooperative knowledge-sharing participating company 1 can be obtained as

$$
\overline{S_{2}^{*}} \quad(1)=\frac{1}{4} a_{2} b_{2}^{-1}(1) c(0) d^{-1}-\frac{1}{2} b_{2}^{-1}(1) \eta \text {. }
$$

For $c(0)>c(1)>0$, combining formula (5) and formula (15), we have

$$
\overline{S_{2}^{*}}(1)>S_{2}^{*}(1)>0 \text {. }
$$

From equation (16), it can be seen that, after noncooperative knowledge-sharing participating company 1 pretends to be a cooperative knowledge-sharing participating company 1 (establishing reputation) in the first period, its optimal signal in the second period is greater than that when reputation is not considered, so 


$$
U_{2}\left(1, \widetilde{S}_{1}^{*}(0), \bar{S}_{2}^{*}(1), A_{2}\left(0, \bar{S}_{2}^{*}(1)\right)\right) \geq U_{2}\left(1, \widetilde{S}_{1}^{*}(0), S_{2}^{*}(1), A_{2}\left(0, S_{2}^{*}(1)\right)\right) .
$$

According to $S_{1}^{*}(0)>S_{1}^{*}(1)>0$, we can analogize

$$
\widetilde{S}_{1}^{*}(0)>S_{1}^{*}(1)>0 \text {. }
$$

It can be seen from equation (18) that the signal sent by noncooperative knowledge-sharing participating company 1 in the first period of establishing a reputation is greater than the optimal signal without considering reputation, and from equation (7), it can be seen that the signal sent in the first period. The greater the signal, the greater the negative effect; then, there are

$$
U_{1}\left(1, \widetilde{S}_{1}^{*}(0), A_{1}\left(0, \widetilde{S}_{1}^{*}(0)\right)\right)<U_{1}\left(1, S_{1}^{*}(1), A_{1}\left(1, S_{1}^{*}(1)\right)\right) .
$$

It can be seen from equation (19) that if a noncooperative knowledge-sharing participating company 1 pretends to be a cooperative one in the first period, its utility in the first period is less than that of the first period without considering the reputation. Then,

And, formula (3) is a strictly increasing function of $S_{1}$.

$$
\begin{aligned}
& U_{2}\left(1, \widetilde{S}_{1}^{*}(0), S_{2}^{*}(1), A_{2}\left(0, S_{2}^{*}(1)\right)\right) \\
& \quad>U_{2}\left(1, S_{1}^{*}(1), S_{2}^{*}(1), A_{2}\left(1, S_{2}^{*}(1)\right)\right) .
\end{aligned}
$$

Combining formula (17) and formula (20), we can get

$$
\begin{aligned}
& U_{2}\left(1, \widetilde{S}_{1}^{*}(0), \bar{S}_{2}^{*}(1), A_{2}\left(0, \bar{S}_{2}^{*}(1)\right)\right) \\
& >U_{2}\left(1, S_{1}^{*}(1), S_{2}^{*}(1), A_{2}\left(1, S_{2}^{*}(1)\right)\right) .
\end{aligned}
$$

From equation (21), it can be seen that noncooperative knowledge-sharing participating company 1 pretends to be the cooperative one in the first period and uses reputation in the second period. So, its utility in the second period is greater than that in the first period, while it does not pretend to be a cooperative knowledge-sharing participating enterprise.

The reputation model based on the signal game in the above two periods explains that to maximize their utility, even noncooperative knowledge-sharing participating companies 1 will always pretend to be the cooperative one in the first period to establish an honest reputation of trustworthiness. However, noncooperative knowledge-sharing participating companies 1 will lose part of their utility in the first period of building a reputation, while in the second period, they will use reputation to gain more utility. One of the implicit assumptions in the article is that when noncooperative knowledge-sharing participating company 1 should have enough patience and confidence to pretend to be the cooperative one. If not, reputation will greatly reduce the incentive effect of knowledge sharing and cooperation between enterprises.

Potters and Winden [33] in their experimental work studied a simple and basic signaling game. Their experimental results showed in the studies that costly messages are being sent most often by 'higher 'sender forms (whose knowledge is such that persuasion is often beneficial to the responder) and have an effect on the responder's conduct. These findings are supported by (versions of) both game and decision models. ICT can also increase knowledge sharing by lowering temporal and spatial barriers amongst knowledge workers and enhancing access to knowledge information. If ICT is analyzed concerning the incentive for information sharing, a more comprehensive perspective will emerge, according to [27].

The quantitative association among innovation, knowledge sharing, and performance was examined by Wang and Wang [34]. Their research model proposes that knowledge sharing has a positive relationship with performance not only directly but also indirectly through its impact on innovation, which leads to firm performance. This study empirically validated utilizing data from 89 high-tech companies in China's Jiangsu Province. Both explicit and implicit knowledge-sharing practices have been found to help with innovation and efficiency.

On the other hand, Sarafopoulos and G.loannidis [29] looked at how two dominant local agents and used collaboration and conflict tactics to increase their payoffs. Signal games are used in the research as a methodological tool to notify actors about possible benefits and risks. The game is supported by two actors: a local government with a high degree of local expertise and a local firm. Local government has considerable clout in the field of local entrepreneurship, and local companies are eager to launch new projects in the region. Signals are used to construct the game, which either ensures payoffs or result in a loss for both actors. The local firm must choose between running the investment project in the local jurisdiction and defecting. Intraregional coordination among local actors determines the choice of equilibrium in the game, resulting in local development conditions. High levels of cooperation between the local government and the company are needed for attracting investment in appropriate conditions. The ability of the local government to successfully enact reforms is the game's most important variable, while Zhang et al.[35] used the signal model to investigate the reputation of aquatic commodity logistics firms. They used the model to look at these businesses in separation and pooling equilibrium as well as provide a static economic overview.

In their recent study, Zhou, Gao, and Chen [31] investigated the signaling game study of group knowledge heterogeneity using a two-period reputation model. The findings indicate that information providers have sufficient motivation to engage in joint activities. The researchers then investigated the factors that influence R\&D team members' willingness to participate in information sharing and developed a theoretical model, which demonstrates that personal reputation, willingness to share, and group identity have different effects on information providers motives in 
organizational learning. Explorative and exploitative learning both have a major effect on collaborative innovation efficiency, with the former having a larger impact than the latter; besides that, team motivation has a controlling impact on the relationship between organizational learning and information collaboration innovation efficiency. External information exchange and knowledge leakage are often strategic issues as companies perform innovation activities [36]. External knowledge sharing has a beneficial impact on innovation success, according to results from a survey of 150 Finnish technology-intensive companies, but high levels of unintentional and deliberate knowledge leakage by a firm's employees negatively moderate this relationship.

Hao et al.[37] stated that effective knowledge sharing is the cornerstone for the supply chain s collaborative activity. They investigated the evolution direction and stable strategies of knowledge-sharing activity between construction supply chain enterprises using evolutionary game theory, as well as the factors that influence the formation of a knowledge-sharing alliance. The findings show that knowledge-sharing activity in construction supply chains takes different evolutionary paths depending on the income connection. Chengyi Xia et al.[38] investigated coordination in adaptive games on interrelated networks, where players in one network layer play the snowdrift game (SDG) and players in the other layer play the prisoner s dilemma game (PDG). Players are able to exchange information across two layers, which have an impact on their strategy decisions. From Monte Carlo simulations, they showed that simply transferring knowledge about the strategy of the competing player in the other network layer is enough to boost overall collaboration considerably. Although coordination is greatly enhanced in the layer where the PDG is played, the opposite is true in the layer where the SDG is played, but to a lesser degree. As a consequence, a double impact of knowledge exchange is responsible for the net increase in cooperation. They also showed that the more accurate the information flow, the higher the overall degree of cooperation, and that this remains true as long as the players information channels do not change over time.

\section{Problems in Knowledge Sharing among Enterprises and Their Solutions}

\subsection{Problems of Knowledge Sharing among Chinese Enterprises}

(1) In Chinese actual economic activities, on-off games make it difficult for companies to generate mutual trust. Knowledge sharing between companies is often a cooperative behavior based on short-term interest, and it is difficult to conduct long-term cooperation. Opportunistic behavior is more common. Therefore, the efficiency of knowledge sharing between enterprises is very low. Based on the social exchange theory, many experts and scholars have pointed out that this economic phenomenon of inefficient knowledge sharing is the result of a lack of trust in society, but its essence is that some companies worry about long-term policy changes during the long-term knowledge-sharing process with other companies. The expected benefits of cooperation bring shadows and uncertainty. Therefore, both parties hope to maximize the benefits of knowledge sharing from one-time or short-term cooperation and lack of incentives for reputation accumulation.

(2) There are often information asymmetries in knowledge sharing among many Chinese enterprises. On the one hand, companies do not know the quantity, quality, and accessibility of their partners' knowledge, and it is also difficult to know whether they are willing to share their knowledge. In this sense, companies are on the weaker side of knowledge ownership; on the other hand, the partners often do not share it easily because of worrying about the uncertainty of the return, which made them become the strong side of knowledge. This has caused information asymmetry between the two parties in terms of possessing knowledge and even sharing knowledge. In practice, many companies use information asymmetry to maximize the infringement of the interest of the partners in transactions. However, due to the limited information, the partners can only observe the noncooperative party's actions to a certain extent and thus believe that the type of noncooperative party is still cooperative.

(3) "The phenomenon of termination of knowledge sharing" among enterprises frequently occurs. On the surface, the reason for this phenomenon is the lack of credit among enterprises. In fact, from the conclusions of the analysis model in this article, it can be seen that the "end-of-knowledge-sharing phenomenon" between enterprises means that the cooperative enterprise has two choices at the final stage of the game: one is to continue to cooperate, and the other is to choose not to cooperate and take advantage of the good reputation which has been established is going to maximize benefits. Therefore, noncooperative companies are more inclined to short-term cooperation, believing that the "termination of knowledge sharing" can maximize benefits at this time. If there is no essential supervision and restraint on cooperative enterprises, even "good" cooperative enterprises may choose noncooperative behavior to erode the interests of other cooperative enterprises.

Starting from the above problems, combined with the analysis model of this article, we can draw the following conclusions: the uncertainty of economic policies is an important reason for the lack of long-term cooperation confidence in knowledge sharing between enterprises, and therefore the cooperative enterprises have no incentive to build a good reputation and then frequent one-off games and short-term games. The result of the one-off game is an essential condition for the lack of cooperation in knowledge 
sharing between enterprises. Short-term cooperation leads to frequent "termination of knowledge sharing." Besides, the asymmetry of information makes cooperative companies use opportunistic behavior to erode the interest of other cooperative companies, and it is difficult for other cooperative companies to verify.

\subsection{Establishing Incentive Conditions for Knowledge Sharing} among Chinese Enterprises. From the analysis of this article, although the reputation effect is very important for the incentive effect of enterprises to participate in knowledge sharing, the function of this mechanism is conditional. To make it play an effective incentive role, it should start from the objective conditions of how to improve the reputation mechanism and seek the best way to achieve it. Combined with the analysis of the problems existing in the process of knowledge sharing between Chinese enterprises, it is recommended to proceed from the following aspects:

(1) Create a continuous and stable economic environment for the cooperation and development of knowledge sharing between enterprises. At present, the economic environment faced by Chinese enterprises is still unsatisfactory. The market economic system is not yet mature and complete, and there are still large loopholes in the economic system which makes the opportunistic behavior of some enterprises more serious. The existence of these factors has greatly hindered enterprises. The cooperation between the two sides, especially the cooperation in knowledge sharing, is helpful. Therefore, a fully sound market economy environment is a prerequisite for enterprises to have confidence in the future economy, and it is also a basic condition for motivating enterprises to accumulate their reputation for a long time.

(2) Encourage enterprises to enhance their social reputation by actively carrying out activities such as protecting the environment, insisting on safe production, and fulfilling social responsibilities, so that their business-related partners can have a comprehensive understanding of them and eliminate the uncertainty of knowledge sharing benefits' risk. With the deepening market reform process going on, many transactions have become one-off or anonymous transactions, and knowledge sharing between enterprises is no exception. In the absence of a pyramidal social trust structure, knowledge sharing between enterprises has more moral hazards and fraudulent behaviors. In the meanwhile, the enterprise's pursuit of reputation is far less meaningful than the short-term benefits of knowledge sharing. Therefore, companies should be encouraged to conduct business from the perspective of long-term benefit expectations, strengthen corporate reputation and belief, and make the goals of all participating companies in knowledge sharing converge.

(3) Establishing an effective communication and coordination mechanism, one of the manifestations is to amplify the corporate reputation effect, allowing potential partners to understand the company more comprehensively and even playing a role in supervising the opportunistic behavior of the company in the knowledge-sharing process. Specifically, the information communication and coordination mechanism can be divided into three levels, namely, the strategic level, the technical level, and the implementation level. At the strategic level, establish a high-level coordination organization to hold various coordination meetings regularly and irregularly and establish a knowledge-sharing participation enterprise appeal system. At the technical level, an information network can be established to build a bridge for communication between the supply and demand sides of knowledge. At the executive level, various interactive activities between enterprises, such as networking parties, picnics, and vacations, can be held to promote knowledge sharing and mutual trust among participating enterprises.

(4) Form a sound enterprise performance information database and social evaluation system. An important condition for the formation of corporate reputation is that the phenomenon of encroaching on the interests of other companies through deception can be discovered in time, so the record of performance information is very important. Society must recognize reputable performance companies so that they can obtain high returns while gaining general recognition from the public. At the same time, establishing a punishment mechanism that will inevitably damage the reputation of violations, so that companies realize that, besides the direct cooperation network, the entire society is a closely connected cooperation network, and the company's breach of contract behavior is restrained, and even unethical companies can be encouraged to actively adopt strategies to maintain reputation.

\section{Conclusion}

The creation of an enterprise's dominant role no longer relies solely on capital and material resources; knowledge resources and organizational cooperation are rapidly becoming essential sources of organizational creativity and core competencies. The $\mathrm{R} \& \mathrm{D}$ team is the most common knowledge collaborative organization structure in the enterprise, and the willingness of team members to innovate defines the enterprise s future growth [31].

To further explore the internal micromechanism of knowledge sharing between enterprises, this paper uses a two-stage reputation model based on the signal game to analyze the influence of reputation effects on knowledge sharing between enterprises. The research results show that, under the incentive of reputation effect, even those noncooperative enterprises adopt cooperative strategies to participate in knowledge sharing between enterprises. The significance of its research conclusions lies in the fact that, under the conditions of a continuous and stable economic 
environment, broad business horizons, smooth information exchange and communication, and sound corporate credit records, reputation effects are an important mechanism to ensure the effective operation of knowledge sharing between enterprises.

The game analysis in the abovementioned two-period reputation model shows that knowledge contributors' collective willingness plays a significant role in knowledge collaborative innovation activities, although knowledge flow within an enterprise is difficult and knowledge collaborative is rarely a normal phenomenon. Human behavior is conditioned by both internal and external influences, as well as cognition and emotions [31]. However, the research of this paper only considers the two-stage signal game process between enterprises in the process of knowledge sharing and does not consider the scenario of multiple game processes between the two parties, which has certain limitations. This will be the direction for the author to carry out follow-up research and further efforts. However, the conclusion of the model analysis in this article is still in line with reality and has strong guiding significance for practice. The signal gaming model can be used to analyze the decisions of commercial banks and medium-sized and small enterprises (SMEs) in supply chain finance business, as well as local government and local firms (local agent's cooperation's), aquatic product logistics companies, etc., as suggested by previous studies.

\section{Data Availability}

The data used to support the findings of this study are available from the corresponding author upon request.

\section{Conflicts of Interest}

The authors declare that they have no conflicts of interest.

\section{Acknowledgments}

This research was funded by the Humanities and Social Sciences Research Project of the Ministry of Education (Grant no. 20YJC630199), Project of Ministry of Education of China (Grant no. 2019ITA01018), Soft Project of Zhejiang Province (Grant No. 2021C35089), Fujian Social Science Planning Project (Grant No. FJ2019B148), and 2021 Annual President's Fund Project of Xiamen University (Grant No. 2072021050).

\section{References}

[1] X. D. Kong, Q. Xu, and T. Zhu, "Dynamic evolution of knowledge sharing behavior among enterprises in the cluster innovation network based on evolutionary game theory," Sustainability, vol. 12, no. 1, pp. 1-23, 2020.

[2] J. Abbas, I. Hussain, S. Hussain, S. Akram, I. Shaheen, and B. Niu, "The impact of knowledge sharing and innovation upon sustainable performance in islamic banks: a mediation analysis through an sem approach," Sustainability, vol. 11, no. 15 , p. $4049,2019$.

[3] X. H. Qian, Y. F. Yang, and W. L. Xu, "Corporate network position, absorptive capacity and innovation performance-an interactive effect model," Management World, vol. 5, pp. 118$129,2010$.

[4] A. Escribano, A. Fosfuri, and J. A. Tribó, "Managing external knowledge flows: the moderating role of absorptive capacity," Research Policy, vol. 38, no. 1, pp. 96-105, 2009.

[5] Y. M. Wang and J. W. Bao, "An evolutionary game analysis of knowledge sharing behavior for cluster supply chai," Science and Technology Management Research, vol. 39, no. 4, pp. 142-149, 2019.

[6] Y. Zhao and X. W. Guo, "A game theoretical analysis of knowledge sharing in strategic alliance," East China Economic Management, vol. 27, no. 7, pp. 108-112, 2013.

[7] S. L. Shi, "Research on influencing factors of common knowledge sharing and private knowledge protection in knowledge alliances," Studies in Science of Science, vol. 26, no. 2, pp. 416-421, 2009.

[8] X. Jiang, Y. Bao, Y. Xie, and S. Gao, "Partner trustworthiness, knowledge flow in strategic alliances, and firm competitiveness: a contingency perspective," Journal of Business Research, vol. 69, no. 2, pp. 804-814, 2016.

[9] Y. Fang, Q. Liang, and Z. Jia, "Knowledge sharing risk warning of industry cluster: an engineering perspective," Systems Engineering Procedia, vol. 2, no. 6, pp. 412-421, 2011.

[10] M. Ramirez and X. Li, "c"searning and sharing in a Chinese high-technology cluster: a study of inter-firm and intra-firm knowledge flows between R\&D employees," New Technology, Work and Employment, vol. 24, no. 3, pp. 277-296, 2009.

[11] E. Hong and L. Rowell, "Challenging knowledge monopoly in education in the U.S. through democratizing knowledge production and dissemination," Educational Action Research, vol. 27, no. 1, pp. 125-143, 2019.

[12] Y. Wang, W. Tang, and R. Zhao, "Information sharing and information concealment in the presence of a dominant retailer," Computers \& Industrial Engineering, vol. 121, no. 7, pp. 36-50, 2018.

[13] B. S. Wu, H. Zhao, and J. Luo, "Micro-mechanism of knowledge sharing in high-tech enterprises," Science Research Management, vol. 33, no. 3, pp. 65-71, 2012.

[14] W. Sheng and A. N. Raymond, "Knowledge sharing: a review and directions for future research," Human Resource Management Review, vol. 20, no. 2, pp. 115-131, 2010.

[15] W. H. Wang, Z. Zhang, and R. L. Cai, "Knowledge synergy effect of inter-organizational synergy management with open innovation,” R\&D Management, vol. 30, no. 5, pp. 38-48, 2018.

[16] Y. Y. Hu, X. Gu, and Q. Cheng, "An empirical study of the mechanism of the knowledge chain synergies," Studies in Science of Science, vol. 33, no. 4, pp. 585-594, 2015.

[17] Q. L. Wang and H. X. Yu, "The moderating effect of environmental turbulence on the relationship between organizational reputation and knowledge sharing in collaborative innovation," Studies in Science of Science, vol. 34, no. 3, pp. 425-432, 2016.

[18] F. C. Lu and P. B. Hu, "Game analysis of reputation mode on cooperation of members in network organizatio," nChina Industrial Economy, vol. 2, pp. 73-79, 2005.

[19] H. Gong, The Research of Portfolio Manager Incentive in Chinese Security Funds, Hunan University, Changsha, China, 2005.

[20] T. J. Xiao and Z. H. Sheng, "Two-period reputation model based on signaling game," Journal of Management Sciences in China, vol. 6, no. 1, pp. 27-31, 2003. 
[21] D. M. Kreps and R. Wilson, "Reputation and imperfect information," Journal of Economic Theory, vol. 27, no. 2, pp. 253-279, 1982.

[22] P. Milgrom and J. Roberts, "Limit pricing and entry under incomplete information: an equilibrium analysis," Econometrica, vol. 50, no. 2, pp. 443-459, 1982.

[23] D. M. Kreps, P. Milgrom, J. Roberts, and R. Wilson, "Rational cooperation in the finitely repeated prisoners dilemma," Journal of Economic Theory, vol. 27, no. 2, pp. 245-252, 1982.

[24] C. Dellarocas, F. Dini, and G. Spagnolo, Designing Reputation (Feedback) Mechanisms, Social Science Electronic Publishing, Rochester, NY, USA, vol.47, pp.1-39, 2006.

[25] C. Roddie, Signaling and Reputation in Repeated Games, I: Finite Games, Social Science Electronic Publishing, Rochester, New York, USA, 2011.

[26] R. J. Arend, "Reputation for cooperation: contingent benefits in alliance activity," Strategic Management Journal, vol. 30, no. 4, pp. 371-385, 2009.

[27] P. Hendriks, "Why share knowledge? The influence of ICT on the motivation for knowledge sharing," Knowledge and Process Management, vol. 6, no. 2, pp. 91-100, 1999.

[28] J. W. Spencer, "Firms' knowledge-sharing strategies in the global innovation system: empirical evidence from the flat panel display industry," Strategic Management Journal, vol. 24, no. 3, pp. 217-233, 2003.

[29] G. Sarafopoulos and P. G. Ioannidis, "Local agents' cooperation as a signal game: firms, local governments and investment strategies," Procedia Economics and Finance, vol. 9, pp. 133-141, 2014.

[30] H. Bar-Isaac, "Reputation and Survival: learning in a dynamic signalling model," Review of Economic Studies, vol. 70, no. 2, pp. 231-251, 2003.

[31] Y. Zhou, S. Gao, and J. Chen, "Motivations of R\&D team participating in knowledge collaboration: a game analysis and empirical study," Journal of Interdisciplinary Mathematics, vol. 21, no. 4, pp. 975-987, 2018.

[32] W. Y. Zhang, Game Theory and Information Economics, Shanghai Joint Publishing Press, Shanghai, China, 1996.

[33] J. Potters and F. Van Winden, "Comparative statics of a signaling game: an experimental study," International Journal of Game Theory, vol. 25, no. 3, pp. 329-353, 1996.

[34] Z. Wang and N. Wang, "Knowledge sharing, innovation and firm performance," Expert Systems with Applications, vol. 39, no. 10, pp. 8899-8908, 2012.

[35] J. S. Zhang, J. L. Zhang, S. W. Liu, and J. N. Mu, “The reputation analysis based on the signal game theory model of the aquatic products of Logistics Company," In International Conference On Computer And Computing Technologies In Agriculture, vol. 3, pp. 419-429, 2011.

[36] P. Ritala, H. Olander, S. Michailova, and K. Husted, "Knowledge sharing, knowledge leaking and relative innovation performance: an empirical study," Technovation, vol. 35, pp. 22-31, 2015.

[37] C. C. Hao, Q. Du, Y. D. Huang, L. Shao, and Y. Q. Yan, "Evolutionary game analysis on knowledge-sharing behavior in the construction supply chain," Sustainability, vol. 11, no. 19, 5319 pages, 2019.

[38] C. Y. Xia, X. P. Li, Z. Wang, and M. Perc, "Doubly effects of information sharing on interdependent network reciprocity," New Journal of Physics, vol. 20, no. 7, pp. 1-10, 2018. 